\title{
Structured education programme for women with polycystic ovary syndrome: a randomised controlled trial
}

\author{
Hamidreza Mani ${ }^{1,2}$, Yogini Chudasama', Michelle Hadjiconstantinou', Danielle H Bodicoat', \\ Charlotte Edwardson ${ }^{1,3}$, Miles J Levy², Laura J Gray4, Janette Barnett' ${ }^{2}$, Heather Daly ${ }^{5}$, Trevor A Howlett ${ }^{2}$, \\ Kamlesh Khunti ${ }^{1}$ and Melanie J Davies ${ }^{1}$ \\ ${ }^{1}$ Diabetes Research Centre, Leicester Diabetes Centre, University of Leicester, Leicester General Hospital, Leicester, UK \\ ${ }^{2}$ Department of Diabetes and Endocrinology, Leicester Royal Infirmary, University Hospitals of Leicester NHS Trust, Leicester, UK \\ ${ }^{3}$ The Leicester Biomedical Research Centre, Leicester and Loughborough, UK \\ ${ }^{4}$ Department of Health Sciences, University of Leicester, Leicester, UK \\ ${ }^{5}$ Leicester Medical Group, Thurmaston Health Centre, Leicester, UK \\ Correspondence should be addressed to H Mani: Hamidreza.mani@uhl-tr.nhs.uk
}

\begin{abstract}
Objective: To evaluate the effectiveness of a structured education programmes in women with polycystic ovary syndrome (PCOS).

Methods: Single-centre, randomised controlled trial, testing a single exposure to a group-based, face-to-face, structured education programme. Inclusion criteria were women with PCOS, aged 18-49 years inclusive and body mass index $\geq 23 \mathrm{~kg} / \mathrm{m}^{2}$ for black and minority ethnicities or $\geq 25 \mathrm{~kg} / \mathrm{m}^{2}$ for white Europeans. Primary outcome was step-count/day at 12 months. Secondary outcomes included indices of physical activity, cardiovascular risk factors, quality of life (QoL) and illness perception (IP).

Results: 161 women were included (78 control, 83 intervention); $69 \%$ white; mean age 33.4 (s.D. 7.6) years, of whom 100 (48 intervention; 52 control) attended their 12-month visit (38\% attrition). $77 \%$ of the intervention arm attended the education programme. No significant change in step-count was observed at 12 months (mean difference: +351 steps/day (95\% confidence interval $-481,+1183) ; P=0.40)$. No differences were found in biochemical or anthropometric outcomes. The education programme improved participants' IP in 2 dimensions: understanding their PCOS $(P<0.001)$ and sense of control $(P<0.01)$ and improved QoL in 3 dimensions: emotions $(P<0.05)$, fertility $(P<0.05)$, weight $(P<0.01)$ and general mental well-being $(P<0.01)$.

Discussion: A single exposure to structured education programme did not increase physical activity or improve biochemical markers in overweight and obese women with PCOS. However, providing a structured education in parallel to routine medical treatment can be beneficial for participants' understanding of their condition, reducing their anxiety and improving their QoL.
\end{abstract}

Key Words
- polycystic ovary syndrome
- structured education
- physical activity
- attrition rate
- quality of life
- illness perception

Endocrine Connections (2018) 7, 26-35

\section{Introduction}

The diagnosis of polycystic ovary syndrome (PCOS) has a major impact on a woman's life in relation to their reproductive health (infertility and pregnancy complication), metabolic health (increased risk of type 2 diabetes (T2D) and cardiovascular risk factors) and mental health issues (reduced QoL, depression and

$$
\begin{array}{lr}
\text { http://www.endocrineconnections.org } & \text { ○ } 2018 \text { The authors } \\
\text { https://doi.org/10.1530/EC-17-0274 } & \text { Published by Bioscientifica Ltd }
\end{array}
$$

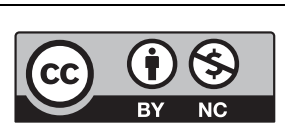

This work is licensed under a Creative Commons Attribution-NonCommercial 4.0 International License. 
anxiety) (1, 2, 3). Women with PCOS have described their challenges in living with PCOS (4) and their dissatisfaction with lack of information around their condition (5). Structured education programmes increase patients' understanding of their condition $(6,7)$ and can address the expressed needs of women with PCOS about lack of information $(4,5)$. Current PCOS guidelines (2) recommend lifestyle change but do not routinely recommend the use of structured education programmes. There is, however, a potential need for this $(5,8,9)$, and we hypothesised that an educational programme using the tested models for T2D (http://www.desmond-project.org.uk), might assist in lifestyle change (for example, increase physical activity) for women with PCOS by improving their understanding of their condition.

\section{Subjects and methods}

We conducted a single-centre, parallel randomised controlled trial (Ethical approval by East Midlands' Research Ethics Committee 11/EM/0141, Clinical Trials.Gov registration number NCT01462864). The intervention was a single seven-hour, group-based, faceto-face structured education programme. The study was powered to detect a mean difference of 2000 steps/day between the arms, based on a previous study in people at risk of diabetes (10), where a similar intervention had increased step-counts by 2000 steps/day (standard deviation (S.D.) $=4000$ steps/day). Aiming for $80 \%$ power, $\alpha=0.05$, s.D. $=4000$ steps $/$ day and allowing for $20 \%$ drop out, 80 participants per arm were needed. All participants consented after full explanation of the study procedure.

\section{Inclusion/exclusion criteria}

Women with a confirmed diagnosis of PCOS (2), body Mass Index (BMI) $\left(\geq 23 \mathrm{~kg} / \mathrm{m}^{2}\right.$ for black and minority; $\geq 25 \mathrm{~kg} / \mathrm{m}^{2}$ for white Europeans) (11), aged 18-49 years inclusive, who had stable PCOS treatment in the previous 6 months were eligible. Exclusion criteria were pregnancy, diabetes, use of corticosteroids, disabling physical or mental condition and inability to speak English.

Participants were recruited (July 2012 to July 2013) from primary care as identified by Read codes in the electronic record, PCOS clinics in the local university hospital and media advertisements.

\section{Study visits and outcome measures}

Visits were performed at the local research centre. At baseline, information on smoking status, ethnicity, medical and family history was obtained by self-report. Fasting blood test and oral glucose tolerance test was performed and questionnaires were filled in.

The Brief Illness Perceptions Questionnaire (BIPQ) (12) was used to test PCOS perception. This nine-item instrument is based on an 11 point scale $(0=$ no effect, $10=$ complete effect) to measure five cognitive illness representations (consequences, timeline, personal control, treatment control and identity), two emotional representations (concern and emotion) and illness comprehensibility (perceived knowledge).

Health-related QoL (HRQoL) was measured using disease-specific and independent generic tools. The disease-specific PCOS questionnaire (PCOSQ) (13), which contains 26 items measures five areas; emotions, body hair, weight, infertility problems and menstrual problems. The independent generic HRQoL questionnaire, version 2 of the Short form F12 (SF12V2) health survey (Optum. com), includes one question for each of the total eight domains (physical functioning, social functioning, physical impairment, emotional impairment, emotions, vitality, pain and global health) (14). The composite score in SF12V2 was calculated using the approved software by the company (Quality.Metrics).

Step-counts and other activity data were objectively measured by the Actigraph GT3X accelerometer (Penascola Florida, USA). At least four days of $\geq 10 \mathrm{~h}$ of accelerometer movement data were required for analysis. KineSoft (version 3.3.76) was used to process the data.

All participants left the centre wearing their accelerometer with a log-book to register their activities. They were instructed to wear the accelerometer for 10 days during the waking hours and return it in a prepaid envelope.

Randomisation occurred after the baseline visit by an independent administrator. Randomisation was 1:1 to the intervention or control arm, stratified for age ( $<35$ years or $\geq 35$ years), ethnicity (white or non-white) and current use of metformin (yes or no). The study was un-blinded due to the nature of the intervention. Participants were blind to their baseline step-counts. They were informed of randomisation after their accelerometer was returned. The intervention group was then invited to attend the next available structured education. The study team did not change the medical treatment for PCOS; both arms continued as before with their own doctors and both

This work is licensed under a Creative Commons Attribution-NonCommercial 4.0 International License. 
received a generic information sheet about PCOS and the benefits of lifestyle change.

Those with blood tests indicative of diabetes had a repeat test and if confirmed, were excluded from the study and referred to their general practitioner.

Follow-up visits had the same structure and were at 6 and 12 months after the baseline visit, irrespective of the education date for the intervention arm; both arms returned at a similar period, eliminating the seasonal effect on outdoor physical activity. The study was concluded in August 2014.

\section{Intervention}

A 'structured education programme to improve cardiovascular risk in women with PCOS, SUCCESS'. The curriculum of the programme considered the available literature $(2,8,15,16,17,18,19,20)$ and was informed by quantitative and qualitative analysis of the target population $(3,4,21)$. The initial drafts of the education programme were piloted in two different cohorts of women with PCOS ( $N=5$ in each cohort) and their feedback was sought and implemented into the final draft $(22,23)$.

The final programme consisted of $7 \mathrm{~h}$ of interactive discussions including patient and professional story, diet and physical activity, balancing life with PCOS and selfmanagement plan (Supplementary Table 1, see section on supplementary data given at the end of this article). Each education session was delivered by two trained educators. Each participant received a resource pack including summary of the points from each section as well as the results of their glucose, lipids, BMI and average walking steps from their baseline visit so they could reflect on their results during the programme. In the section 'Balancing life with PCOS' (Supplementary Table 1), participants had the opportunity to share their feelings towards PCOS.

At the end of the session, participants were asked to reflect on the day.

\section{Statistical analysis}

Descriptive characteristics are presented as means and S.D. or medians with ranges for continuous variables depending on their distribution, and as number and percentages for categorical variables. Outcome data were assessed for normality using visual inspection of histograms. Per-protocol analysis was used, which excluded the participants who did not attend the structured education or were lost to follow-up. For the

$$
\begin{array}{lr}
\text { http://www.endocrineconnections.org } & \odot 2018 \text { The authors } \\
\text { http://doi.org/10.1530/EC-17-0274 } & \text { Published by Bioscientifica Ltd }
\end{array}
$$

primary outcome, the mean change in steps per day at 12 months was compared between treatment arms using a linear regression model, adjusted for the stratification variables, change in accelerometer wear time and baseline step-count (Stata, version 14.0). Sensitivity analyses included complete case and intention-to-treat analysis. Subgroup analyses and secondary outcomes were analysed in a similar manner and graphically displayed with the estimated difference of steps between treatment groups with 95\% confidence interval. Statistical significance was set at $5 \%$ for main effects with two-sided $P$ values. Statistical analyses were performed using Stata (version 14.0).

The Supplementary Methods contains further details of the methodology of sensitivity analyses as well as 6-month data.

\section{Results}

We recruited 161 participants (78 controls, 83 intervention) (Fig. 1), mean age 33.4 (s.D. 7.6) years and 68.9\% white ethnicity. Overall, 47.5\% were working full time, 31.9\% part time and $6.3 \%$ were students. Median baseline stepcounts for the control and intervention arms were 6294 and 6353 steps/day, respectively (Table 1). Overall, 22\% of the participants were current smokers.

Mean (s.D.) days from baseline to six- and 12-month visits were 217 (39) and 399 (44) for the education arm, and 207 (39) and 389 (30) days for the control arm $(P=0.117$ and $P=0.179$ for six and 12 months, respectively). For the 65 (77\%) women who attended education, the mean (s.D.) time from baseline appointment to education was 90 (54) days. At 12 months, attendance was 58\% $(n=48)$ in control arm and $67 \%(n=52)$ in the education (intervention) arm amounting to $38 \%$ total dropout.

The mean difference in change in step-counts/ day at 12 months was +351 (95\% confidence interval: $-481,1183)$ in those receiving the intervention compared to control, with similar results in sensitivity analyses (Table 2). Subgroup analysis for stratification factors, source of recruitment and duration of the PCOS $(<5,5-10$, and $>10$ years $)$ showed no difference in outcome (Supplementary Fig. 1). The activity log indicated that almost half of the participants had taken off their monitors during potentially relevant activities such as swimming, spinning class, running and partying: $47 \%$ in the education arm and $50 \%$ in the control. None, however, had recorded the time duration for these activities.

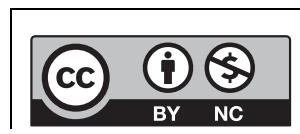

This work is licensed under a Creative Commons Attribution-NonCommercial 4.0 International License. 


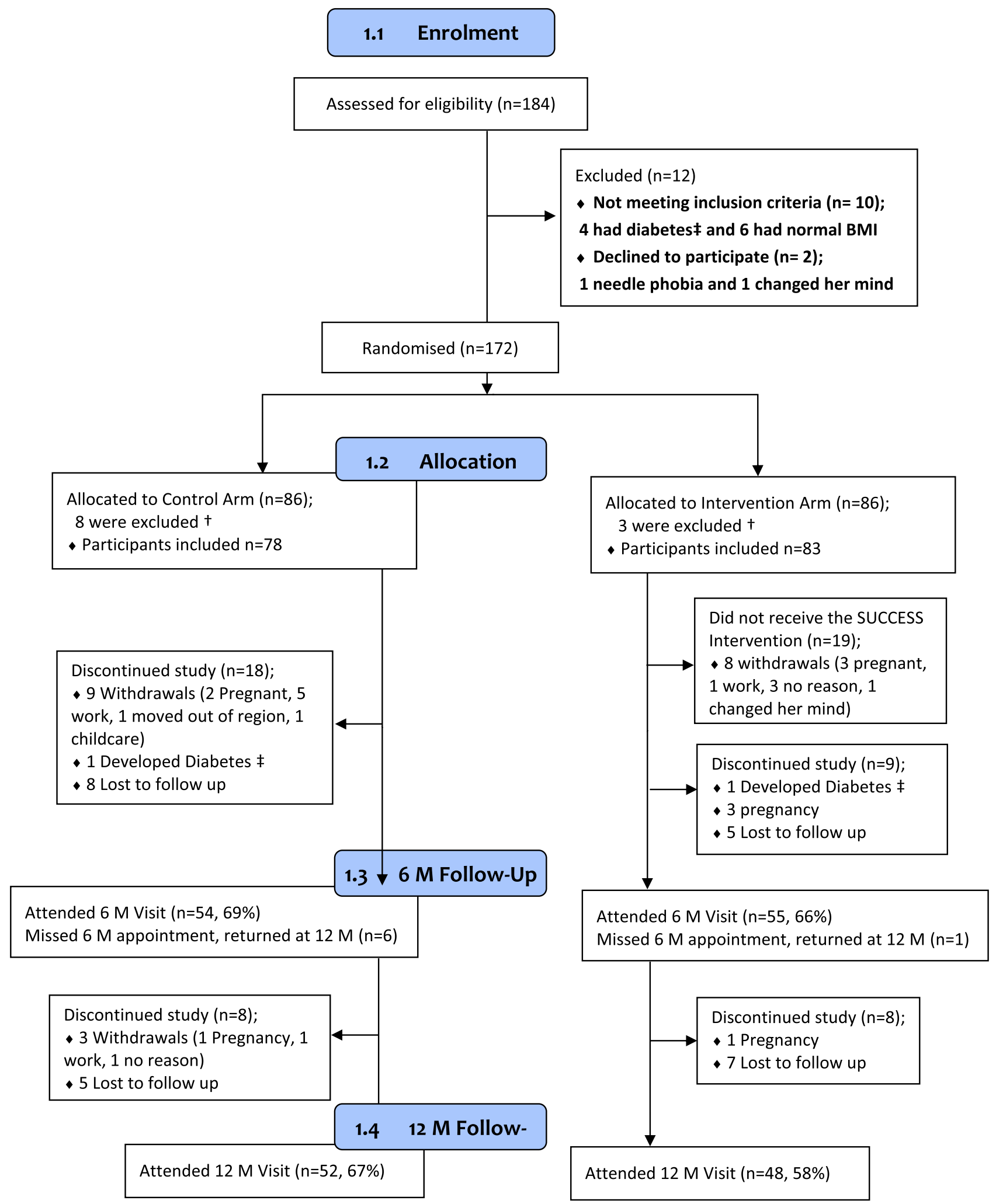

Figure 1

CONSORT flow diagram (http://www.consort-statement.org/) for the participants in SUCCESS study. BMI, Body Mass Index. "Participants with diabetes were referred to a diabetes education programme. ${ }^{\dagger}$ Did not meet the BMI eligibility criteria and had been incorrectly randomised.

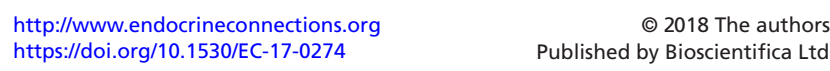


Table 1 Baseline characteristics of participants; values are presented as means (s.D.), medians (lower and upper quartiles) or as otherwise stated.

\begin{tabular}{|c|c|c|}
\hline Characteristics & Control $(n=78)$ & Intervention $(n=83)$ \\
\hline Age (years) & $33.3(8.1)$ & $33.4(7.1)$ \\
\hline \multicolumn{3}{|l|}{ No $(\%)$} \\
\hline European & $53(67.9)$ & $58(69.9)$ \\
\hline South Asian & $17(21.8)$ & $14(16.9)$ \\
\hline Other & $8(10.3)$ & $11(13.3)$ \\
\hline No $(\%)$ working full time & $48(62.3)$ & $46(55.4)$ \\
\hline No $(\%)$ current smokers & $15(19.2)$ & $21(25.3)$ \\
\hline No $(\%)$ depression & $28(35.9)$ & $29(34.9)$ \\
\hline No (\%) metformin & $15(19.2)$ & $17(20.5)$ \\
\hline \multicolumn{3}{|l|}{ Recruitment } \\
\hline Primary care & $44(56.4)$ & $51(61.5)$ \\
\hline Secondary care & $13(16.7)$ & $9(10.8)$ \\
\hline Self-referral & $21(26.9)$ & $23(27.7)$ \\
\hline \multicolumn{3}{|l|}{ Year of PCOS diagnosis } \\
\hline$<5$ years & $25(32.1)$ & $25(30.1)$ \\
\hline $5-10$ years & $13(16.7)$ & $26(31.3)$ \\
\hline$>10$ years & $40(51.3)$ & $32(38.6)$ \\
\hline \multicolumn{3}{|l|}{ Biometric measurements } \\
\hline Weight (kg) & $89.0(19.6)$ & $90.9(18.9)$ \\
\hline Body Mass Index $\left(\mathrm{kg} / \mathrm{m}^{2}\right)$ & $33.2(6.2)$ & $34.2(7.2)$ \\
\hline Systolic blood pressure $(\mathrm{mmHg})$ & $121.7(11.5)$ & $122.5(13.1)$ \\
\hline Diastolic blood pressure $(\mathrm{mmHg})$ & $77.1(10.6)$ & $80.4(11.9)$ \\
\hline Fasting glucose (mmol/L) & $4.8(0.4)$ & $4.8(0.5)$ \\
\hline 2-h glucose (mmol/L) & $5.9(1.4)$ & $5.8(1.8)$ \\
\hline Haemoglobin $A_{1 c}(\%)$ & $5.7(0.4)$ & $5.7(0.4)$ \\
\hline Haemoglobin $A_{1 c}(\mathrm{mmol} / \mathrm{mol})$ & $38.7(4.2)$ & $39.2(4.0)$ \\
\hline Total cholesterol (mmol/L) & $5.2(0.9)$ & $5.0(1.0)$ \\
\hline $\mathrm{HDL}(\mathrm{mmol} / \mathrm{L})$ & $1.5(0.5)$ & $1.4(0.4)$ \\
\hline $\mathrm{LDL}(\mathrm{mmol} / \mathrm{L})$ & $3.2(0.9)$ & $3.0(0.8)$ \\
\hline Triglycerides (mmol/L) & $1.3(0.6)$ & $1.4(0.7)$ \\
\hline HOMA-IR & $2.5(1.6)$ & $2.8(2.3)$ \\
\hline Sex Hormone Binding Globulin (mmol/L) & $47.0(40.3)$ & $56.9(48.4)$ \\
\hline Free Androgen Index (\%) & $6.5(6.0)$ & $6.8(5.4)$ \\
\hline \multicolumn{3}{|l|}{ Physical activity } \\
\hline Steps (counts/day) & $6294(4785-8478)$ & $6353(5147-7521)$ \\
\hline Light PA (min/day) & $262.3(226.8-318.2)$ & $278.5(228.2-341.9)$ \\
\hline MVPA (min/day) & $28.7(12.5-40.7)$ & $26.5(16.2-41.1)$ \\
\hline Sedentary (min/day) & $526.3(479.0-580.9)$ & $532.4(473.1-578.4)$ \\
\hline Accelerometer wear time (min/day) & $832.4(779.6-886.0)$ & $849.7(799.5-877.6)$ \\
\hline
\end{tabular}

Missing data: 0 age, ethnicity, depression, multimorbidity, weight, BMI, metformin; 1 working, systolic blood pressure, diastolic blood pressure; 2 total cholesterol, HDL, triglycerides, SHBG; 3 fasting glucose, HbA1C, LDL; 4 2-h glucose; 13 HOMA-IR; 23 steps, light PA, MVPA, sedentary, FAl; 80 current smoker.

No clinically significant changes in BMI, lipids, glucose indices and other indices of physical activity were found (Table 3 and also Supplementary Tables 2 and 3).

The education programme significantly improved participants' 'understanding' $(P<0.001)$ and 'control' $(P=0.002)$ of their condition (Table 4). The intervention also improved their QoL in three dimensions of PCOSQ; 'emotions', 'fertility' and 'weight' $(P=0.035, P=0.035$ and $P=0.009$ respectively) as well as the mental component score from the SF-12 questionnaire; mean difference 5.79 (95\% CI 1.74, 9.84, $P=0.006$ ).
() 2018 The authors Published by Bioscientifica Ltd
Participants' had feelings of 'loneliness', 'annoyance', 'ashamed', 'confused', 'depressed' or 'fear' about their PCOS as well as sense of 'relief' after having a diagnosis. Supplementary Figure 2 shows an example of their reflection and Fig. 2 the word cloud summary (http://www.wordle.net/).

On reflection on the education programme, participants' 'best bits' were 'meeting others with PCOS' and 'gaining knowledge about the condition and lifestyle' and 'key messages' were 'being positive about PCOS', 'benefits of the diet and exercise' and the 'concept of insulin resistance'.

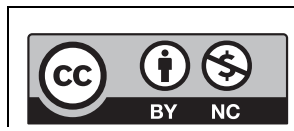

This work is licensed under a Creative Commons Attribution-NonCommercial 4.0 International License. 
Table 2 Change in the number of steps at 6- and 12-months and treatment difference between participants randomised to usual care (control) or the structured education (intervention).

\begin{tabular}{|c|c|c|}
\hline & \multicolumn{2}{|c|}{ Number of participants } \\
\hline & Control & Intervention \\
\hline \multicolumn{3}{|l|}{ Per protocolc,d } \\
\hline 6-months & 42 & 40 \\
\hline 12-months & 38 & 34 \\
\hline \multicolumn{3}{|c|}{ Complete case ${ }^{c}$} \\
\hline 6-months & 42 & 42 \\
\hline 12-months & 38 & 34 \\
\hline \multicolumn{3}{|c|}{ Intention to treat ${ }^{\mathrm{e}}$} \\
\hline 6-months & 78 & 83 \\
\hline 12-months & 78 & 83 \\
\hline
\end{tabular}

\begin{tabular}{ccc}
\hline \multicolumn{2}{c}{ Mean change from baseline $(95 \% \mathrm{Cl})$} \\
\cline { 1 - 2 } Control & & Intervention \\
$-240(-869,390)$ & & $792(134,1450)$ \\
$325(-365,1016)$ & & $651(51,1251)$ \\
& & \\
$-240(-869,390)$ & & $751(122,1380)$ \\
$325(-364,1015)$ & & $651(51,1251)$ \\
& & \\
$-205(-856,446)$ & & $707(84,1331)$ \\
$238(-428,904)$ & $744(-8,1497)$ \\
\hline
\end{tabular}

\begin{tabular}{|c|c|}
\hline \multicolumn{2}{|c|}{ Model summarya } \\
\hline Coefficient $(95 \% \mathrm{Cl})$ & $P$ value $^{\mathrm{b}}$ \\
\hline $751(-80,1529)$ & 0.076 \\
\hline $351(-481,1183)$ & 0.402 \\
\hline $721(-88,1530)$ & 0.080 \\
\hline $351(-480,1183)$ & 0.402 \\
\hline $703(-71,1476)$ & 0.074 \\
\hline $318(-566,1203)$ & 0.473 \\
\hline
\end{tabular}

aMean difference, adjusted for baseline value, stratification categories (age, ethnicity, metformin) and change in accelerometer wear time; ${ }^{\mathrm{b}}$ significance of the intervention term in the model; ' those with missing data excluded; ${ }^{\mathrm{d}}$ those who did not attend the structured education programme have been excluded from the intervention arm; ${ }^{\mathrm{e}}$ multiple imputation for missing data.

$\mathrm{Cl}$, confidence interval.

\section{Discussion}

A single exposure to a structured education programme did not increase physical activity or improve biochemical markers in overweight and obese women with PCOS. It did, however, improve mental health and well-being in secondary outcome analyses.

To our knowledge, no other structured education programme exists, which addresses multidimensional needs of women with PCOS and therefore direct comparison with literature was not possible. However, elements of the programme can be compared.

In a single arm study (24), women with PCOS were encouraged to increase their walking activity, which improved fitness but not BMI or cholesterol.
Successful studies in women with PCOS have had multiple sessions of supervised exercise (18), which is not pragmatic in routine clinical practice. Structured education programmes in non-PCOS cohorts have had mixed outcomes: improved physical activity in an older cohort (average age $>60$ years) (10) or no change in a younger, mixed gender group (average age $<35$ years) (25). Multiple, weekly sessions in women (not necessarily those with PCOS) have increased walking activity by 2000 steps (26). In our study, we aimed for a larger cohort and offered one exposure to the education programme, following the then recommendations for diabetes (27). Current recommendations are different and suggest a minimum of $16 \mathrm{~h} /$ year contact time

Table 3 Changes in anthropometric and biomedical outcomes at 12 months follow-up.

Weight $(\mathrm{kg})$
BMI (kg/m²)
Systolic blood pressure $(\mathrm{mmHg})$
Diastolic blood pressure $(\mathrm{mmHg})$
Fasting glucose (mmol/L)
2-h glucose (mmol/L)
Haemoglobin $\mathrm{A}_{1 \mathrm{c}}(\mathrm{mmol} / \mathrm{mol})$
Insulin (IU/L)
HOMA-IR
Total cholesterol (mmol/L)
HDL cholesterol (mmol/L)
LDL cholesterol (mmol/L)
Triglyceride (mmol/L)
SHBG (mmol/L)
Testosterone (nmol/L)
Vitamin D (ng/mL)

\begin{tabular}{|c|c|}
\hline \multicolumn{2}{|c|}{ No. of participants } \\
\hline Control & Intervention \\
\hline 52 & 48 \\
\hline 52 & 48 \\
\hline 52 & 48 \\
\hline 52 & 48 \\
\hline 52 & 48 \\
\hline 51 & 47 \\
\hline 52 & 48 \\
\hline 47 & 40 \\
\hline 47 & 40 \\
\hline 51 & 48 \\
\hline 51 & 47 \\
\hline 51 & 46 \\
\hline 51 & 48 \\
\hline 51 & 47 \\
\hline 49 & 47 \\
\hline 51 & 47 \\
\hline
\end{tabular}

\begin{tabular}{ccc}
\hline \multicolumn{2}{c}{ Mean change from baseline $(95 \% \mathrm{Cl})$} \\
\hline Control & & Intervention \\
\cline { 1 - 1 }$-0.43(-2.54,1.69)$ & & $-1.74(-3.61,0.14)$ \\
$-0.12(-0.88,0.63)$ & & $-0.66(-1.34,0.02)$ \\
$-3.17(-6.24,-0.10)$ & & $-2.70(-6.00,0.57)$ \\
$-1.13(-3.70,1.43)$ & & $-2.24(-4.78,-0.30)$ \\
$0.04(-0.07,0.16)$ & & $0.03(-0.06,0.11)$ \\
$-0.66(-1.06,-0.25)$ & & $-0.26(-0.77,0.25)$ \\
$-4.06(-4.92,-3.20)$ & & $-5.66(-7.41,-3.90)$ \\
$-1.73(-3.23,-0.24)$ & $-1.48(-4.10,1.13)$ \\
$-0.38(-0.73,-0.04)$ & $-0.29(-0.92,0.34)$ \\
$-0.13(-0.33,0.07)$ & & $-0.23(-0.44,-0.02)$ \\
$0.02(-0.06,0.09)$ & & $-0.02(-0.10,0.06)$ \\
$-0.16(-0.34,0.01)$ & & $-0.17(-0.34,-0.002)$ \\
$0.06(-0.13,0.24)$ & $-0.20(-0.38,0.02)$ \\
$-1.45(-10.02,7.12)$ & $1.70(-8.89,12.30)$ \\
$0.10(-0.20,0.40)$ & $-0.002(-0.20,0.20)$ \\
$12.90(6.28,19.52)$ & $5.83(-0.28,11.94)$ \\
\hline
\end{tabular}

\begin{tabular}{|c|c|}
\hline \multicolumn{2}{|c|}{ Model summary ${ }^{a}$} \\
\hline Coefficient $(95 \% \mathrm{Cl})$ & $P$ value $^{\mathrm{b}}$ \\
\hline-1 & זעם \\
\hline$-0.56(-1.57,0$ & \\
\hline $0.49(-3$. & \\
\hline $0.40(-3$ & 0.822 \\
\hline$-0.01(-0$ & .865 \\
\hline & \\
\hline-1.0 & \\
\hline $0.54(-1$ & 0.640 \\
\hline 0.1 & 554 \\
\hline-0.1 & \\
\hline-0.0 & 0. \\
\hline-0.0 & 0.726 \\
\hline$-0.15(-c$ & \\
\hline $5.01(-7.08,17.10)$ & \\
\hline $0.01(-0.34,0.35)$ & \\
\hline$-7.85(-16.15,0.45)$ & 0.063 \\
\hline
\end{tabular}

${ }^{a}$ Difference between treatment groups, adjusted for baseline value, stratification categories (age, ethnicity, metformin); ${ }^{\text {s }}$ ignificance of the intervention term in the model.

$\mathrm{Cl}$, confidence interval; SHBG, Sex Hormone-Binding Globulin.

$$
\begin{array}{lr}
\text { http://www.endocrineconnections.org } & \text { ○ } 2018 \text { The authors } \\
\text { https://doi.org/10.1530/EC-17-0274 } & \text { Published by Bioscientifica Ltd }
\end{array}
$$


Table 4 Scores for belief in illness, health-related quality of life and SF-12 at 12 months follow.

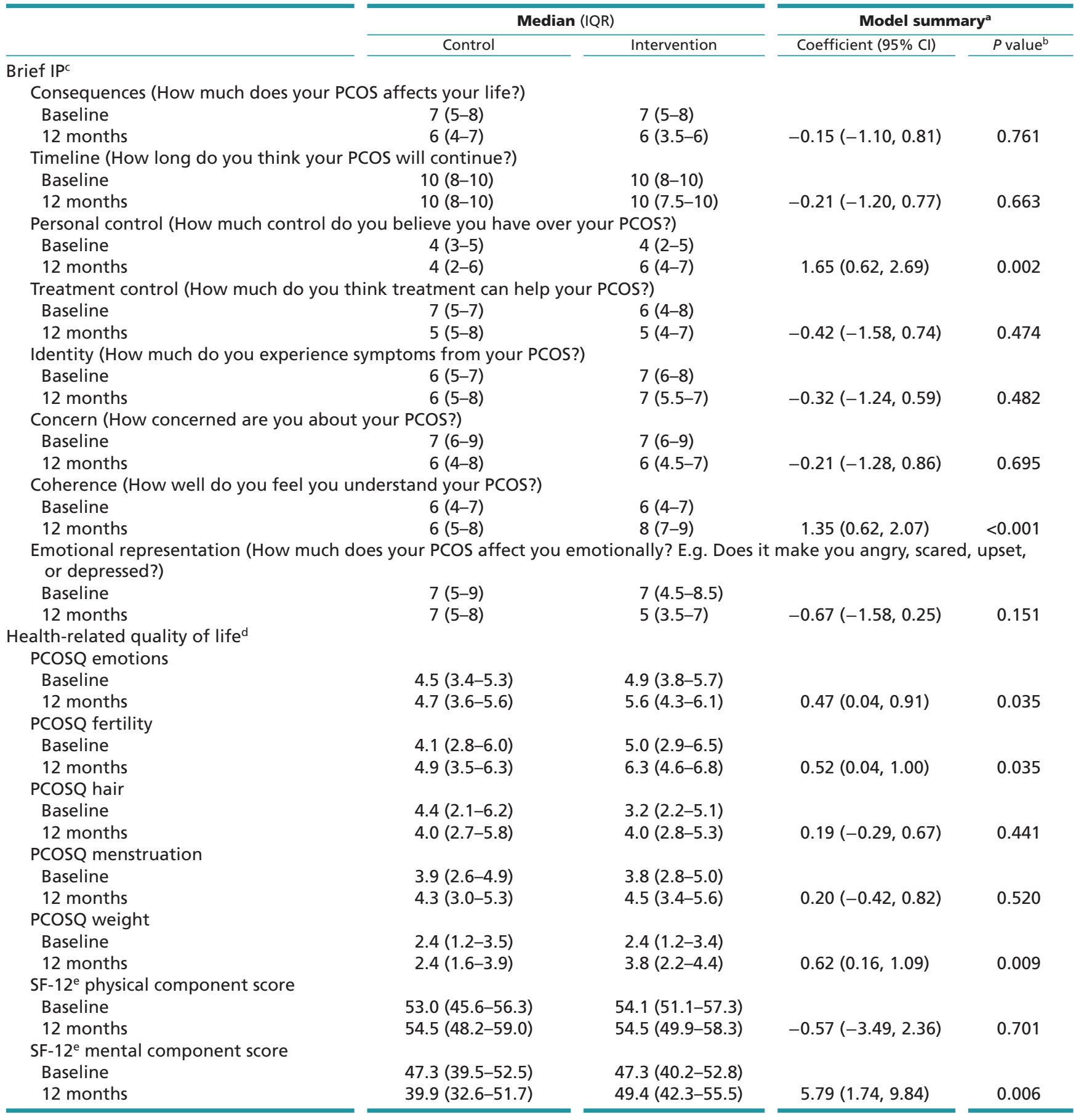

${ }^{a}$ Difference between treatment groups, adjusted for baseline value, stratification categories (age, ethnicity, metformin); ${ }^{b}$ significance of the intervention term in the model; cbrief illness perception questionnaire: scoring out of 10 ( $N=68$, control 31 , intervention 37$)$; dPCOS questionnaire: scoring out of 7 ( $N=89$, control 44, intervention 45); higher scores suggests that PCOS does not have an impact on the quality of life; eSF-12 questionnaire: scoring out of $100(N=89$, control 45, intervention 44); higher scores indicate a better level of health.

$\mathrm{Cl}$, confidence interval; IQR, interquartile range; PCOSQ, PCOS questionnaire.

(28). In our cohort, the 6-month results are slightly more favourable than 12 months. This is perhaps an indication of the short-term impact of such educational interventions and the need for reminder sessions or

$$
\begin{array}{lr}
\text { http://www.endocrineconnections.org } & \text { ○ } 2018 \text { The authors } \\
\text { https://doi.org/10.1530/EC-17-0274 } & \text { Published by Bioscientifica Ltd }
\end{array}
$$

breaking the 7-h education to shorter session to be delivered over a longer period of time.

Structured education in other chronic conditions has shown to improve IP and/or QoL $(29,30,31)$.

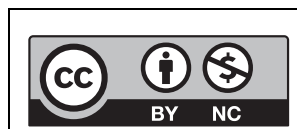

This work is licensed under a Creative Commons Attribution-NonCommercial 4.0 International License. 


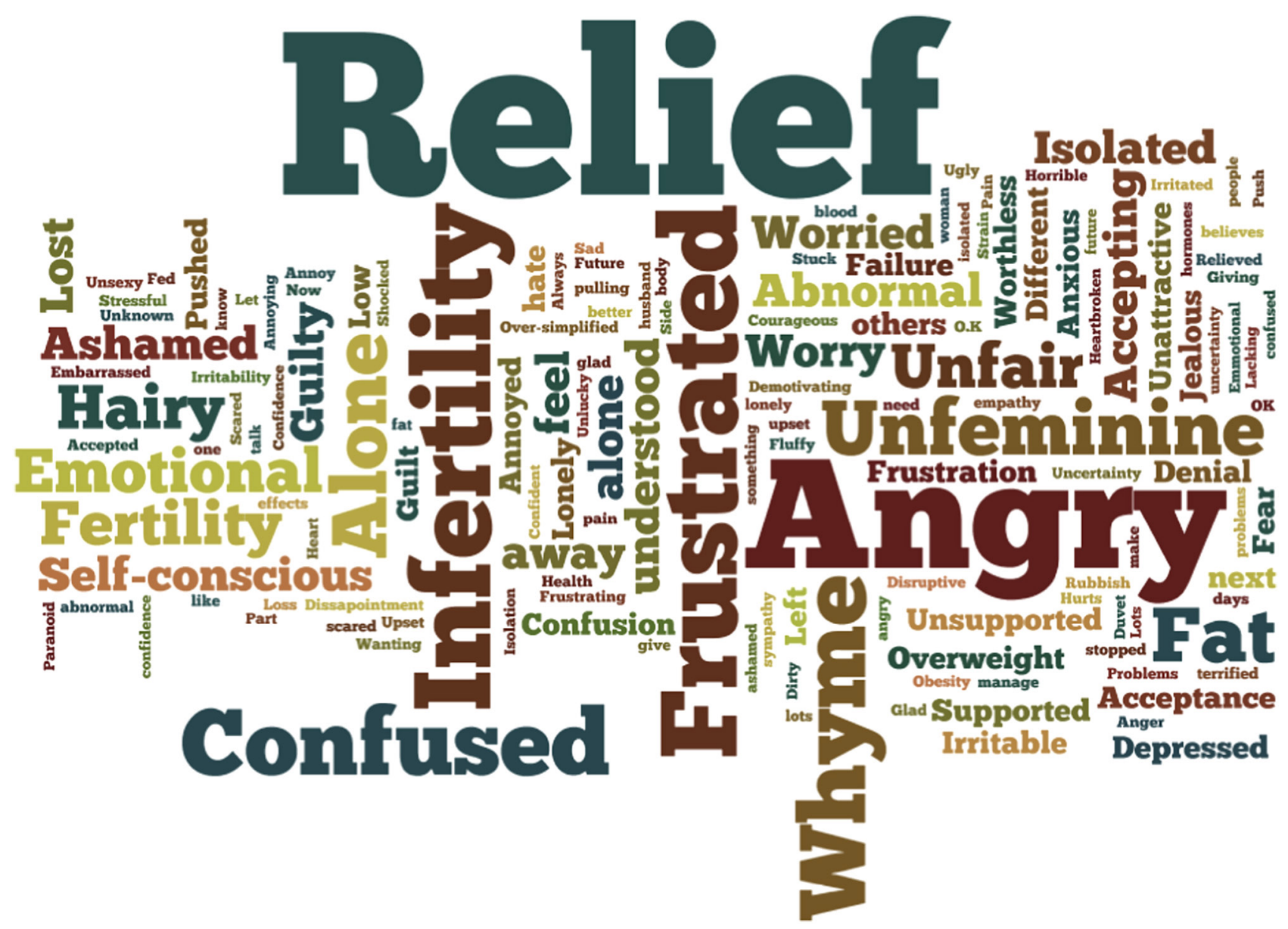

Figure 2

Word cloud summary of feelings of women with PCOS towards their condition and when they found out they had PCOS http://www.wordle.net/. (Larger words have been repeated more frequently.)

Reported feelings of living with PCOS, namely anger, confusion and frustration (Fig. 2), were examples of the psychological challenge that some of the participants experienced. Sense of relief after being diagnosed with PCOS was perhaps a reflection of the psychological impact of the symptoms and an indication of the reported lack of information for these women $(5,8,9)$. It is suggested that such psychological factors are potential barriers for successful lifestyle interventions and require further addressing (9). It is therefore possible to assume that provision of an education programme like our study, at an earlier opportunity as close to the time of diagnosis, can improve well-being by improving IP (coherence and control) and reducing their anxiety around emotions, fertility and weight.

Participants in the SUCCESS education programme indicated meeting other people with PCOS as one of the 'best bits' of the education. Attending group education has had the potential benefit of meeting others with a similar condition, which in fact reduced their anxiety of 'why me', 'unfair' and feeling 'lonely'. Providing structured group education for chronic conditions with a potential element of peer support can improve the outcome of other treatment interventions.

\section{Strength and limitations}

The major limitation of the study was the high attrition rate (38\%) at the end of study (32\% at 6 month follow-up). It is worth noting that only $23 \%$ of the intervention arm did not attend the education. This could be an indication of their information need; they spared time for the education, while competing life activities (85\% employed or student) perhaps prevented attendance at the clinical visits.

Second major limitation for the primary outcome was the use of the accelerometer. Although a useful tool to capture physical activities, it contributed to substantial

$$
\begin{array}{lr}
\begin{array}{l}
\text { http://www.endocrineconnections.org } \\
\text { https://doi.org/10.1530/EC-17-0274 }
\end{array} & \text { ○ } 2018 \text { The authors } \\
\end{array}
$$

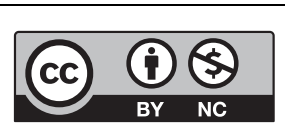

This work is licensed under a Creative Commons Attribution-NonCommercial 4.0 International License. 
missing data in our study due to loss in the post, strict validity criteria and inability to capture some activities (e.g. cycling and swimming).

Considering that this was the first attempt at developing a tailored education programme for women with PCOS and the high prevalence of overweight and obesity in PCOS $(2,21)$, the inclusion criteria were limited to overweight and obese women to ensure a more metabolically homogenous cohort. The study design, however, avoided any interference with participants' routine medical care and therefore the education programme can potentially be implemented in the speciality clinics or primary care services similarly.

\section{Conclusion and implications}

The outcomes of our study are important in the provision of care for women affected by PCOS; providing information in a structured approach to ensure improved IP should be part of the treatment offered to women with PCOS especially in the context of patient-centred care. Although a single exposure to structured education did not improve physical activity, BMI or biochemical markers. It did, however, improve their understanding of their disease and their QoL. Interim reminder sessions might have improved these outcomes and should be further explored in future research.

In implementation of our findings, we aim to make education sessions available for all of our patients with PCOS in a more regular basis; sign post them to the currently available support groups and in future funding applications consider the design of web-based education interventions in conjunction with the group-based interventions.

\section{Supplementary data}

This is linked to the online version of the paper at https://doi.org/10.1530/ EC-17-0274.

\section{Declaration of interest}

The authors declare that there is no conflict of interest that could be perceived as prejudicing the impartiality of the research reported.

\section{Funding}

Supported by Diabetes Research Centre, University of Leicester, through funds from National Institute for Health Research (NIHR) and NIHR Collaboration for Leadership in Applied Health Research and Care East Midlands and the NIHR Leicester - Biomedical Research Centre, a partnership between University Hospitals of Leicester NHS Trust,
Loughborough University and the University of Leicester. 'Early Career Grant' from Society for Endocrinology (HM). (The views expressed are those of the authors and not necessarily the above mentioned organisations).

\section{Author contribution statement}

Conception of the research question was by $\mathrm{H} \mathrm{M}, \mathrm{H} \mathrm{D}, \mathrm{M} \mathrm{J} \mathrm{D} \mathrm{and} \mathrm{K} \mathrm{K}$; analysis by $Y$ C, D B and L G. C E processed the accelerometer data. H M, J $\mathrm{B}, \mathrm{H} \mathrm{D}$ and $\mathrm{M} \mathrm{H}$ developed the education programme. Paper was drafted by $\mathrm{H} \mathrm{M}$ and reviewed and commented by all authors.

\section{Acknowledgments}

Authors acknowledge the help from patients and wider team at Leicester Diabetes Centre; nurses, administrators, management, education and creative art design group.

\section{References}

1 Barry JA, Kuczmierczyk AR \& Hardiman PJ. Anxiety and depression in polycystic ovary syndrome: a systematic review and meta-analysis. Human Reproduction 201126 2442-2451. (https://doi.org/10.1093/ humrep/der197)

2 Fauser BC, Tarlatzis BC, Rebar RW, Legro RS, Balen AH, Lobo R, Carmina E, Chang J, Yildiz BO, Laven JS, et al. Consensus on women's health aspects of polycystic ovary syndrome (PCOS): the Amsterdam ESHRE/ASRM-Sponsored 3rd PCOS Consensus Workshop Group. Fertility and Sterility 201297 28.e25-38.e25. (https://doi. org/10.1016/j.fertnstert.2011.09.024)

3 Mani H, Levy MJ, Davies MJ, Morris DH, Gray LJ, Bankart J, Blackledge H, Khunti K \& Howlett TA. Diabetes and cardiovascular events in women with polycystic ovary syndrome: a 20-year retrospective cohort study. Clinical Endocrinology 201378 926-934. (https://doi.org/10.1111/cen.12068)

4 Hadjiconstantinou M, Mani H, Patel N, Levy M, Davies MJ, Khunti K \& Stone M. Views of women with polycystic ovary syndrome: a qualitative study in an ethnically diverse sample. Endocrine Connections 20176 323-330. (https://doi.org/10.1530/EC-17-0053)

5 Gibson-Helm M, Teede H, Dunaif A \& Dokras A. Delayed diagnosis and a lack of information associated with dissatisfaction in women with polycystic ovary syndrome. Journal of Clinical Endocrinology and Metabolism 2016102 604-612. (https://doi.org/10.1210/jc.20162963)

6 De Silva D. Evidence: Helping people help themselves London, UK: Health Foundation, 2011. (available at: http://www.health.org.uk/ sites/health/files/HelpingPeopleHelpThemselves.pdf)

7 NICE . The most appropriate means of generic and specific interventions to support attitude and behaviour change at population and community levels. NICE Public health guideline 6 [PH6]. London, UK: NICE, 2007. (available at: https://www.nice.org. uk/ph6)

8 Mani H, Khunti K, Daly H, Barnett J \& Davies M. Education and selfmanagement for women with polycystic ovary syndrome; a narrative review of literature. Ibnosina Journal of Medicine and Biomedical Sciences 20157 1-9. (https://doi.org/10.4103/1947-489X.210263)

9 Brennan L, Teede H, Skouteris H, Linardon J, Hill B \& Moran L. Lifestyle and behavioral management of polycystic ovary syndrome. Journal of Women's Health 201726 836-848. (https://doi.org/10.1089/ jwh.2016.5792)

10 Yates T, Davies M, Gorely T, Bull F \& Khunti K. Effectiveness of a pragmatic education program designed to promote walking activity in individuals with impaired glucose tolerance: a randomized controlled trial. Diabetes Care 200932 1404-1410. (https://doi. org/10.2337/dc09-0130)

$$
\begin{array}{lr}
\text { http://www.endocrineconnections.org } & \text { () } 2018 \text { The authors } \\
\text { https://doi.org/10.1530/EC-17-0274 } & \text { Published by Bioscientifica Ltd }
\end{array}
$$

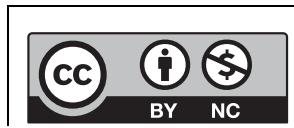


11 NICE . Assessing body mass index and waist circumference thresholds for intervening to prevent ill health and premature death among adults from black, Asian and other minority ethnic groups in the UK. NICE Public health guideline [PH46]. London, UK: NICE, 2013. (available at: https://www.nice.org.uk/guidance/ph46)

12 Broadbent E, Petrie KJ, Main J \& Weinman J. The brief illness perception questionnaire. Journal of Psychosomatic Research $2006 \mathbf{6 0}$ 631-637. (https://doi.org/10.1016/j.jpsychores.2005.10.020)

13 Cronin L, Guyatt G, Griffith L, Wong E, Azziz R, Futterweit W, Cook D \& Dunaif A. Development of a health-related quality-of-life questionnaire (PCOSQ) for women with polycystic ovary syndrome (PCOS). Journal of Clinical Endocrinology and Metabolism $1998 \mathbf{8 3}$ 1976-1987. (https://doi.org/10.1210/jcem.83.6.4990)

14 Ware J Jr, Kosinski M \& Keller SD. A 12-item short-form health survey: construction of scales and preliminary tests of reliability and validity. Medical Care 199634 220-233. (https://doi. org/10.1097/00005650-199603000-00003)

15 Mani H, Potdar N \& Gleeson H. How to manage an adolescent girl presenting with features of polycystic ovary syndrome (PCOS); an exemplar for adolescent health care in endocrinology. Clinical Endocrinology 201481 652-656. (https://doi.org/10.1111/cen.12501)

16 Mani H, Khunti K, Levy M \& Davies M. Diabetes advice for women with polycystic ovary syndrome; prevention, prevention, prevention. Diabetes Management 20133 1-14. (https://doi.org/10.2217/ dmt.13.54)

17 Moran LJ, Ko H, Misso M, Marsh K, Noakes M, Talbot M, Frearson M, Thondan M, Stepto N \& Teede HJ. Dietary composition in the treatment of polycystic ovary syndrome: a systematic review to inform evidence-based guidelines. Journal of the Academy of Nutrition and Dietetics 2013113 520-545. (https://doi.org/10.1016/j. jand.2012.11.018)

18 Moran LJ, Hutchison SK, Norman RJ \& Teede HJ. Lifestyle changes in women with polycystic ovary syndrome. Cochrane Database of Systematic Reviews 2011 CD007506. (https://doi. org/10.1002/14651858.CD007506.pub3)

19 Moran LJ, Pasquali R, Teede HJ, Hoeger KM \& Norman RJ. Treatment of obesity in polycystic ovary syndrome: a position statement of the Androgen Excess and Polycystic Ovary Syndrome Society. Fertility and Sterility 200992 1966-1982. (https://doi.org/10.1016/j. fertnstert.2008.09.018)

20 Harrison CL, Lombard CB, Moran LJ \& Teede HJ. Exercise therapy in polycystic ovary syndrome: a systematic review. Human Reproduction Update 201117 171-183. (https://doi.org/10.1093/humupd/ dmq045)

21 Mani H, Davies MJ, Bodicoat DH, Levy MJ, Gray LJ, Howlett TA \& Khunti K. Clinical characteristics of polycystic ovary syndrome: investigating differences in White and South Asian women. Clinical Endocrinology 201583 542-549. (https://doi.org/10.1111/cen.12784)
22 Mani H. Development of a structured education programme to improve cardiovascular risk in women with polycystic ovary syndrome. PhD Thesis, University of Leicester, 2014. (available at: https://lra.le.ac.uk/handle/2381/28638)

23 Mani H, Daly H, Barnett J, Levy M, Khunti K, Howlett T \& Davies M. The development of a structured education programme to improve cardiovascular risk in women with polycystic ovary syndrome (SUCCESS Study). Endocrine Abstracts 201331 P228. (https://doi. org/10.1530/endoabs.31.P228)

24 Randeva HS, Lewandowski KC, Drzewoski J, Brooke-Wavell K, O'Callaghan C, Czupryniak L, Hillhouse EW \& Prelevic GM. Exercise decreases plasma total homocysteine in overweight young women with polycystic ovary syndrome. Journal of Clinical Endocrinology and Metabolism 200287 4496-4501. (https://doi.org/10.1210/jc.2001012056)

25 Biddle SJ, Edwardson CL, Wilmot EG, Yates T, Gorely T, Bodicoat DH, Ashra N, Khunti K, Nimmo MA \& Davies MJ. A randomised controlled trial to reduce sedentary time in young adults at risk of type 2 diabetes mellitus: project STAND (Sedentary Time ANd Diabetes). PLoS ONE 201510 e0143398. (https://doi.org/10.1371/ journal.pone.0143398)

26 Clarke KK, Freeland-Graves J, Klohe-Lehman DM, Milani TJ, Nuss HJ \& Laffrey S. Promotion of physical activity in low-income mothers using pedometers. Journal of the American Dietetic Association 2007 107 962-967. (https://doi.org/10.1016/j.jada.2007.03.010)

27 Haas L, Maryniuk M, Beck J, Cox CE, Duker P, Edwards L, Fisher EB, Hanson L, Kent D, Kolb L, et al. National standards for diabetes self-management education and support. Diabetes Care 201235 2393-2401. (https://doi.org/10.2337/dc12-1707)

28 NICE . Preventing type 2 diabetes: risk identification and interventions for individuals at high risk. NICE Public health guidance [PH38]. London, UK: NICE, 2012. (available at: https://www.nice.org.uk/guidance/ph38)

29 Davies MJ, Heller S, Skinner TC, Campbell MJ, Carey ME, Cradock S, Dallosso HM, Daly H, Doherty Y, Eaton S, et al. Effectiveness of the diabetes education and self management for ongoing and newly diagnosed (DESMOND) programme for people with newly diagnosed type 2 diabetes: cluster randomised controlled trial. BMJ 2008336 491-495. (https://doi.org/10.1136/bmj.39474.922025.BE)

30 Zwerink M, Brusse-Keizer M, van der Valk PD, Zielhuis GA, Monninkhof EM, van der Palen J, Frith PA \& Effing T. Self management for patients with chronic obstructive pulmonary disease. Cochrane Database of Systematic Reviews 2014 CD002990. (https://doi.org/10.1002/14651858.CD002990.pub3)

31 Kroon FP, van der Burg LR, Buchbinder R, Osborne RH, Johnston RV $\&$ Pitt V. Self-management education programmes for osteoarthritis. Cochrane Database of Systematic Reviews 2014 CD008963. (https://doi. org/10.1002/14651858.CD008963.pub2)

Received in final form 9 November 2017

Accepted 10 November 2017

Accepted Preprint published online 13 November 2017 http://www.endocrineconnections.org https://doi.org/10.1530/EC-17-0274 (c) 2018 The authors Published by Bioscientifica Ltd

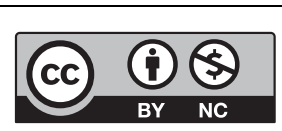

This work is licensed under a Creative Commons Attribution-NonCommercial 4.0 International License. 